Ind. Health, 1.974, 12, 97.

\title{
AVERAGED AUDITORY EVOKED RESPONSE (AER) IN RAT INTOXICATED WITH GASOLINE
}

\author{
Kazuo SAITO, Nobuyuki KAMITA and Eimatsu TAKAKUWA \\ Department of Hygiene and Preventive Medicine, Hokkaido University School of Medicine, \\ Kita 15 Nishi 7, Kita-Ku, Sapporo, Japan.
}

(Received July 1, 1974)

Averaged auditory evoked response (AER) from the brain surface in rats injected intraabdominally with three kinds of gasoline: nonleaded white gasoline (WG), tetraethyl lead containing gasoline (LG), and gasoline containing tetraethyl lead, benzene, toluene, and xylene (LBTX), was analysed.

Aftear the gasoline injection the mean peak latency of each wave in AER was delayed in direct proportion to the degree of poisoning. The amplitude of AER also increased or decreased proportionally to the degree of gasoline intoxication. In the WG group, AER showed little variation in latency and amplitude. However, in the LG group, characteristic delay in latency and decreased amplitude of AER were observed. In the LBTX group, one to three days after injection, AER variation was similar but larger than the VER of the LG group. When the rat was in a moveless lethargic condition the peak latencies of the positive and the negative waves were remarkably delayed and the amplitudes increased.

The poisonous and anesthetic effects of gasoline on the synaps and on the nerve cells were very strong in the order of $\mathbf{W G}<\mathbf{L G}<$ LBTX.

The recording of corebral evoked responses caused by light, sound or some electrical stimuli is widely used as a method to get information on cerebral functions and the processes of attention and decision in people and animals ${ }^{1-6)}$.

Brain waves evoked by light and sound can be recorded by summation or averaging techniques ${ }^{7,8)}$. There are four electrical elements indicating a cerebral evoked response: 1) the impulse of afferent nerves, 2) the discharge from any kind of neuron, 3 ) the post-synaptic potentials, and 4) the electrical activity of dendrites. When the stimulus from a peripheral sensory nerve get close to the cerebral cortex, the latency of the cerebral evoked potential is delayed according to the degree of deceleration experimented by the impulse in synapses. The cerebral evoked potential produces an electrical biphasic wave, generally in the following order: a negative wave (I), a positive wave (II), another negative wave (III), and another positive wave (IV). That is, an oscillatory sequence showing a rather large and repetitive fluctuation. In the case of auditory evoked responses (AER) the components of I, II and III are called primary reaction'; they are signal waves which flow through the auditory afferent route into the 


\section{K. SAITO, N. KAMITA AND E. TAKAKUWA}

auditory area of the cortex. The components of the fourth (IV) and following waves are called 'secondary reaction'. According to Ciganek ${ }^{9,10)}$ they are due to the activity of the diffuse projection systems in the cortex.

The fourth wave (IV) is also called 'delayed reaction I'11). The following wave, 'delayed reaction II' is a rhythmical potential; the activity of this wave appears to be related to the activity of the delayed circuit in the cortex and to the thalamo-cortical reverberating circuit ${ }^{12}$. It has been reported that this reaction disappears under anaesthesia ${ }^{13)}$ as a consequence of hypofunction of the brainstem reticular formation. On the other hand, when hyperfunction occurs the rhythmical potentials increase remarkably.

We have already reported on the clinical symptoms, survival rate, electrocorticogram (E. Co. G.) and lead content in organs of rats, injected into the abdominal cavity with different types of gasoline ${ }^{14 \sim 16)}$. The present report is based on further studies on the effectiveness of averaged auditory evoked response (AER) as a measure of the degree of intoxication in the central nervous system, and its relationship to specific clinical symptoms and electrocorticographical patterns in rats injected with three different kinds of gasoline.

\section{Material And Methods}

The skulls of 24 white male Wistar rats aged 7 months and weighting about $400 \mathrm{~g}$, were drilled under Nembutalether anaesthesia about $3 \mathrm{~mm}$ from the left side of the sagittal suture at points $1.5 \mathrm{~mm}$ above and below the coronary suture. Bipolar electrodes having a small socket for a transistor and with a silver globular tip of $0.7 \mathrm{~mm}$ in diameter to protect the cortex from injury, were implanted on the surface of the brain about $3 \mathrm{~mm}$ apart over the frontal and occipital lobes of the left hemisphere. The electrodes were attached to the skull permanently with dental cement.

One month after recovery from the implant operation the rats were divided into three groups, the first group containing 7, the second group 12 and the third group 5. These rats were injected intraabdominally with gasoline in a dose of $1 \mathrm{ml}$ per $100 \mathrm{~g}$ of body weight. The first group was given nonleaded white gasoline (WG), the second group, nonleaded gasoline containing $1,000 \mathrm{ppm}$ tetraethyl lead (LG) and the third group LG containing 5\% benzene, $10 \%$ toluene and 15\% xylene (LBTX). Tetraethyl lead contents of LG and LBTX were $1.0 \mathrm{ml}$ per liter and $0.7 \mathrm{ml}$ per liter respectively, that is, $16.5 \mathrm{mg}$ and $11.6 \mathrm{mg}$ per $\mathrm{kg}$ of body weight respectively.

Electrocorticogram (E. Co. G.) was recorded before and one, two, three, four, five, seven, and ten days after injection in a electrically shielded chamber with a 13-channel electroencephalograph (Nihon Kohden Model ME 132B). Averaged auditory evoked response (AER) to a series of 100 clicks presented at $70 \mathrm{~dB}$ hearing level, $1,000 \mathrm{~Hz}$ in frequency and $50 \mathrm{msec}$ in duration was computed (Nihon Kohden Model ATAC 501). The clicks were produced by Noise Field Generator (Rion Model SF-02) connected to a 


\section{AER OF GASOLINE INTOXICATION}

Decade Oscillator (Kikusui Electronics Corp. Model $415 \mathrm{R}-\mathrm{C}$ ) and to a Electronic Stimulator (Nihon Kohden Model MSE-3R). AER was printed using a camera, and the digital number after A-D exchange was typewritten with a data writer. The peak latencies and the peak-to-peak amplitudes of AER were measured from these data.

\section{Results}

Fig. 1 shows the typical AER of rat in rest before gasoline injection. The mean peak latencies of the first negative wave $\left(\mathrm{N}_{1}\right)$, the first positive wave $\left(\mathrm{P}_{1}\right)$ and the second negative wave $\left(\mathrm{N}_{2}\right)$ were $28.7 \mathrm{msec}, 47.1 \mathrm{msec}$ and $66.6 \mathrm{msec}$ respectively. The peak-topeak amplitudes of $\mathrm{N}_{1}-\mathrm{P}_{1}$ and $\mathrm{P}_{1}-\mathrm{N}_{2}$ were $25.2 \mu \mathrm{V}$ and $29.6 \mu \mathrm{V}$ on average.

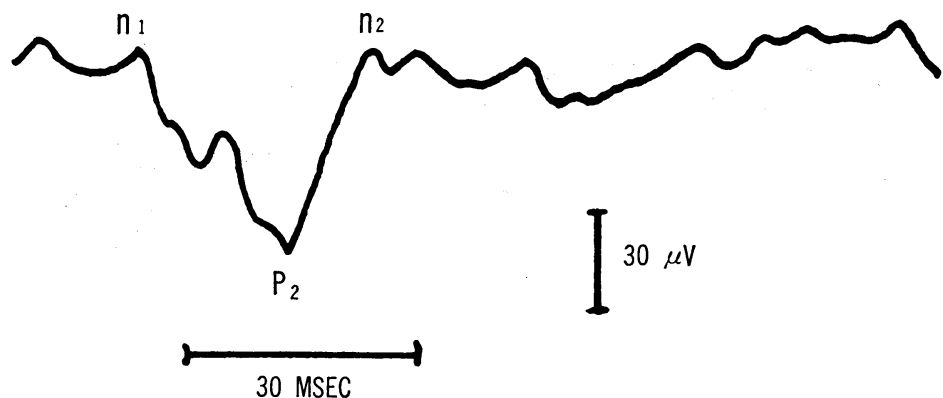

Fig. 1. A schematic pattern of averaged auditory evoked response (AER) in rat before gasoline injection.

As shown in Fig. 2 the shapes of AER vary characteristically in each group according to the time elapsed after gasoline injection. One day after WG, LG and LBTX injection rats showed slowing of movements and a crouching posture. The peak latencies $\mathrm{N}_{1}, \mathrm{P}_{1}$ and $\mathrm{N}_{2}$ in AER were extended while amplitude decreased. In the WG group the latency and amplitude of AER changed slightly in comparison to those before injection. However, the basic pattern, before and after injection, is almost homogeneously maintained except for the first day after injection. No special changes were recognized in the secondary response.

In the LG group the extention of latency and the decrease of amplitude in AER were clealy visible. However, the basic pattern was not recognized on the first, fourth, fifth, seventh and tenth day after injection. The amplitude of the positive wave on the fourth or fifth day. The characteristic pattern in AER disappeared and a simple thythmic wave was recorded on the tenth day when rats showed excessive tension and excitement.

In the LBTX group the faint pattern of AER was observed on the first day after injection while latency extended greatly. The rhythmic after-discharge, which showed comparatively big amplitude, was also recorded in AER. The peak latencies of $N_{1}, P_{1}$ 


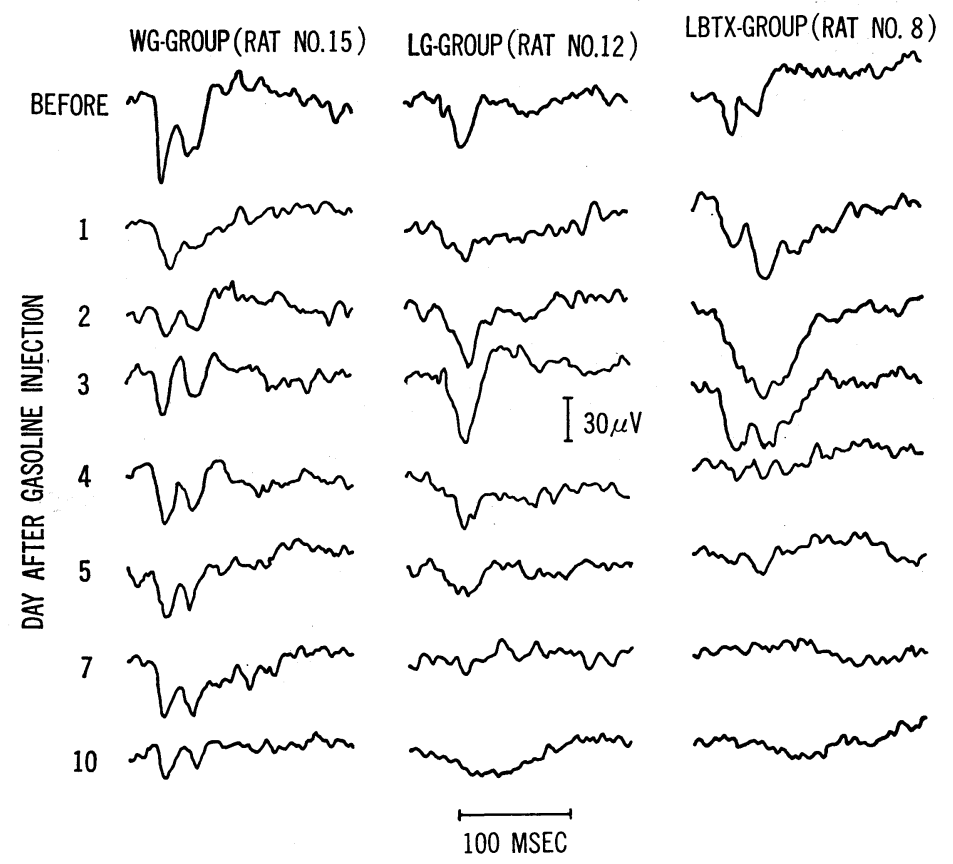

Fig. 2. AER of WG-, LG-, and LBTX-group before and after gasoline injection.

WG: nonleaded white gasoline, LG: $1000 \mathrm{ppm}$ tetraethyl lead containing nonleaded white gasoline, LBTX: tetraethyl lead, benzene, toluene and xylene containing gasoline.

and $\mathrm{N}_{2}$ extended on the second or third day and big amplitude of AER was recorded. This wave disappeared and big negative and positive waves appeared in the secondary component in AER on the fourth or fifth day. On the seventh day, these waves became smaller and disappeared on the tenth day. Then, AER changed into a rhythmic wave with a small swell.

Fig. 3 shows AER of a dead rat in the LBTX group at the normal state before injection, $9 \mathrm{hr}$, and one day after gasoline injection. The peak latencies, at the resting state before injection, of $\mathrm{N}_{1}, \mathrm{P}_{1}$ and $\mathrm{N}_{2}$ were $27.6 \mathrm{msec}, 61.2 \mathrm{msec}$ and $80.2 \mathrm{msec}$, and the peak-to-peak amplitudes of $\mathrm{N}_{1}-\mathrm{P}_{1}$ and $\mathrm{P}_{1}-\mathrm{N}_{2}$ were 69.8 and $70.5 \mu \mathrm{V}$ respectively. Nine hours after injection the rat showing of movements, a crouching posture and delirium $\mathrm{N}_{1}, \mathrm{P}_{1}$ and $\mathrm{N}_{2}$ reached $33.6,88.8$ and $112.8 \mathrm{msec}$ respectively. $\mathrm{N}_{1}-\mathrm{P}_{1}$ and $\mathrm{P}_{1}-\mathrm{N}_{1}$ went up to 90.9 and $81.0 \mu \mathrm{V}$ respectively. Furthermore, after-discharge with big amplitude appeared. Just before death a delirium state developed $\mathrm{N}_{1}, \mathrm{P}_{1}$ and $\mathrm{N}_{2}$ were 22.0, 68.0 and $82.4 \mathrm{msec}$ respectively; $\mathrm{N}_{1}-\mathrm{P}_{1}$ and $\mathrm{P}_{1}-\mathrm{N}_{2}$ decreased to 30.6 and $26.3 \mu \mathrm{V}$; and AER like an almost straight line was recorded. After death E.Co.G. and AER disappeared completely. 


\section{AER OF GASOLINE INTOXICATION}

LBTX-GROUP (RAT NO.9)

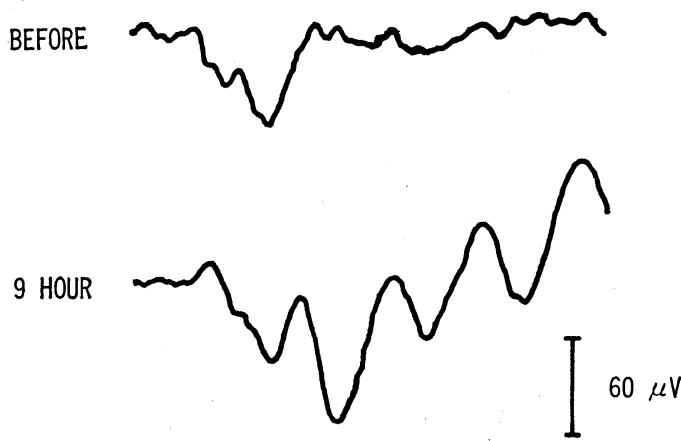

ONE DAY

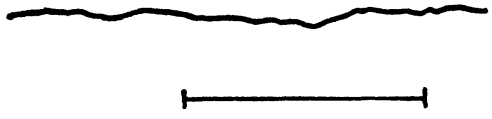

100 MSEC

Fig. 3. Changes of AER in rat under severe condition before death. Before, $9 \mathrm{hr}$, and 1 day after LBTX injection.

\section{Discussion}

Our reports on gasoline intoxication showed the characteristic clinical symptoms which were nystagmus and convulsion of extremities in rats injected with commercially available regular gasoline (RG) and high octane gasoline (HG), excessive excitement and tension in rats injected with LG, and narcotic state with delirium in rats injected with LBTX. E. Co. G. showed a marked decrease of basic rhythm in the first half of the ten day experimental period, especially in the HG and LBTX groups. This phenomenon persisted through the latter half. Before death, rats showed a specific E. Co. G. pattern. In the WG group the decreased basic rhythm recovered gradually, and normal brain waves were recorded since the fifth day after injection. On the seventh day after injection the E. Co. G. of the LG group showed a marked increase of alpha wave provoked by excessive excitement ${ }^{14 \sim 16)}$.

In this experiment, the elongation of the latencies of $N_{1}, P_{1}, N_{2}$ waves in AER is pressumed to be produced by the influence of the anesthetic action of gasoline on the central nervous systems. When the sound stimulus reaches the auditory area in the cortex, the primary reaction occurs. The elongation of peak latency of AER in the LBTX group was the most remarkable. As the anesthetic effect of the organic solvents in gasoline on the central nervous system is far more stronger than that of olefin or naphthene types of carbon hydrates, the influence of LBTX on the synaps and the nervous cells was stronger than that of any other gasoline. 


\section{K. SAITO, N. KAMITA AND E. TAKAKUWA}

On the first day after gasoline injection the amplitudes of AER in the WG, LG and LBTX groups decreased. This can be attributed to the fact that the gasoline injected into the abdominal cavity was initially absorbed by the liver, the kidney and other visceral organs, being stagnated and disposed by their mighty antidotal action. Therefore, the anesthetic action of gasoline did not affect the central nervous system in the preliminary stages. However, stronger inhition in the cortex, due to afferent nerve discharge from abdomen, affected AER. On the second or third day after gasoline injection, as the antidotal activity was impaired, rats became very susceptible to the action of gasoline on their central nervous systems. The amplitude of AER was markedly enlarged due to the fact that inhibition in the brain dose not affect the evoked potential from the cortex ${ }^{17)}$. On the fourth, fifth and seventh day, the WG group which began to recover from their acute gasoline poisoning, regained the normal pattern of their basic brain waves. In the LG group the primary reaction disappeared gradually, and from the seventh to the tenth day rats showed marked symptoms of excitement and tension. The fact that AER could not be recorded at all in the LG group can be attributed to the excessive stimulation of the brainstem reticularformation provoked by tetraethyl lead ${ }^{15)}$. The intensification of the effect of lead affecting the brainstem reticularformation, strengthen the inhibition of the cortex. Furthermore, the reaction of the cortex is weakened by the anesthetic effect of gasoline, therefore, the refractory period is extended ${ }^{18)}$, and the reception of the sound stimuli impaired.

In the LBTX group on the fourth, fifth and seventh day, the secondary reaction was stronger than the primary reaction. The anesthetic action of the organic solvents in LBTX is much more stronger than the stimulative action of tetraethyl lead ${ }^{16)}$. Moreover, because of the hypofunction of the brainstem and the cortex, the reaction to the sound stimuli declined remarkably. The delayed reaction of the rhythmical potentials is thought to be produced as a result of delayed connections in the cortex and the thalamo-cortical reverberating circuits ${ }^{12,13)}$ which reacted to the sound stimuli. On the tenth day after injection, due to severe symptoms of poisoning and deep anesthesia, even this delayed reaction became unnoticeable. Rats in this group which died within the first two days after gasoline injection in a moveless and delirium state, showed remarkably delay of the latencies of the negative and positive impairement of all nervous units. The fact that the rhythmical waves with the larger amplitudes occured during the primary, secondary and delayed reaction, gives an idea of the degree of disturbance in the control mechanism of the central nervous system. As the rats' state became severe, the critical and control function performed by their nervous system was still further impaired, vanishing with death. At this state AER becomes an straight line.

\section{Conclusion}

Averaged auditory evoked response (AER) from the brain surface in rats injected with gasoline changed in proportion to the degree of gasoline intoxication. Measur- 


\section{AER OF GASOLINE INTOXICATION}

ing of latencies and amplitudes in AER is much effective to make a diagnosis of poisoning in concern with central nervous activity.

\section{REFERENCES}

1) Tokizane, T. (1962). Japanese Handbook of Physiology V, Physiology of Brain and Nerve, 25, Igakushoin Ltd., Tokyo. (in Japanese)

2) Jouvet, M., Schott, B., Courjon, J. et Allegre, G. (1959). Revue Neurologique, 100, 437.

3) Jane, J.A., Smirnov, G.D. and Jasper, H.H. (1962). Electroenceph. Clin. Neurophysiol., 14, 334.

4) Davis, H. (1964). Science, 145, 182.

5) Picton, T.W., Hillyard, S.A., Galambos, R. and Schiff, M. (1971). Science, 173, 351.

6) Saito, K. and Takakuwa, E. (1973). Jap. J. Hyg., 28, 340. (in Japanese).

7) Dawson, G.D. (1950). Brit. Med. Bull., 6, 326.

8) Weitzman, E.D. and Kremen, H. (1965). Electroenceph. Clin. Neurophysiol., 18, 65.

9) Ciganek, L. (1961). Electroenceph. Clin. Neurophysiol., 13, 165.

10) Ciganek, L. (1965). Electroenceph. Clin. Neurophysicl., 18, 625.

11) Forbes, A. and Morison, B.R. (1939). J. Neurophysiol., 2, 112.

12) Chang, H.T. (1950). J. Neurophysiol., 13, 235.

13) Fuster, J.M. and Docter, R.F. (1962). J. Neurophysiol., 25, 325.

14) Saito, K., Inai, H. and Takakuwa, E. (1972). Jap. J. Ind. Health, 14, 9. (in Japanese)

15) Saito, K. (1973). Brit. J. Ind. Med., 30, 352.

16) Saito, K. and Takakuwa, E. (1974). Jap. J. Ind. Health, 16, 3. (in Japanese)

17) Schwartz, M., Shagass, C., Bittle, R. and Flapan, M. (1962). Electroenceph. Clin. Neurophysiol., 14, 898 .

18) Bremer, F. and Stoupel, N. (1959). Arch. Int. Physiol. Biochem., 67, 240. 